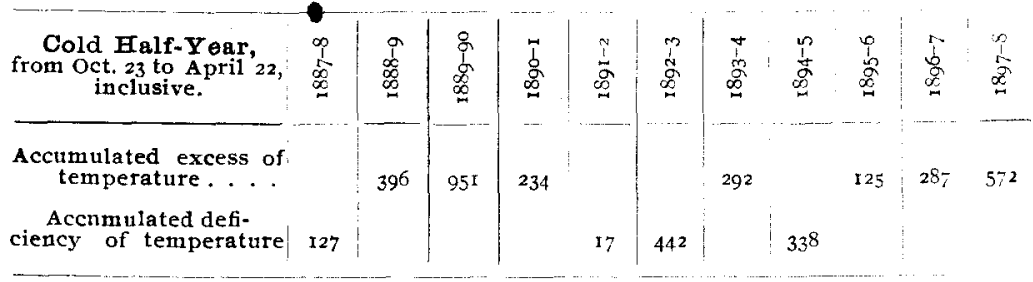

As a further standard of comparison, it may be stated that the winter of I889-90 was much the warmest of any shown by the Philadelphia records for seventy-two years past.

Respectfully,

HeNRY GAWTHROP.

\title{
Franklin Institute.
}

\section{[Proceedings of the slated meeting held Wednesday, May 18, 1898.] \\ HALL OF THE FRANKLIN INSTITUTE, PhILADEI,PHIA, May 18 , I 898 .}

The President, Mr. JoHN BIRkinbine, in the chair.

Present, 2 ro members and visitors.

Additions to membership since last report, 5 .

Mr. Wm. F. Roberts supplemented his communication of last month, on the carbon dioxide engine, by a description of a condensing engine of the same type. An exhibition of the operation of this apparatus, which had been contemplated, was deferred until the June meeting.

Mr. W. S. Ryan, of the Philadelphia Museums, made an extemporaneons address on the Philippine Islands, giving some account of the Islands, their inhabitants, and the administration of the group by the government of Spain. Prof. Wm. P. Wilson, Director of the Museums, supplemented these remarks with an account of the productions of the Islands, and statistics of their trade and commerce.

Mr. E. D. Meier, engineer-in-chief of the Diesel Motor Company, New York, read a paper on the Diesel Motor, illustrating the subject with the aid diagrams. (Referred for publication.) The subject was referred, for investigation and report, to the Committee on Science and the Arts.

Adjourned.

WM. H. WaHL, Secretary.

\section{COMMITTEE ON SCIENCE AND THE ARTS.}

[Abstract of proceedings of the stated meeting held Wednesday, May 4, 1898.]

Prof. L. F. Rondinelia in the chair.

Reports on the following subjects were considered :

Severy Impression Process.-Melvin L. Severy, Boston, Mass. Passed first reading. 